\title{
Scoping a PIM System: A Supporting Framework
}

\author{
Battistello, Loris; Kristjansdottir, Katrin; Hvam, Lars
}

Published in:

2018 IEEE International Conference on Industrial Engineering and Engineering Management

Link to article, DOI:

10.1109/IEEM.2018.8607348

Publication date:

2019

Document Version

Peer reviewed version

Link back to DTU Orbit

Citation (APA):

Battistello, L., Kristjansdottir, K., \& Hvam, L. (2019). Scoping a PIM System: A Supporting Framework. In 2018 IEEE International Conference on Industrial Engineering and Engineering Management (pp. 1831-1835). IEEE. https://doi.org/10.1109/IEEM.2018.8607348

\section{General rights}

Copyright and moral rights for the publications made accessible in the public portal are retained by the authors and/or other copyright owners and it is a condition of accessing publications that users recognise and abide by the legal requirements associated with these rights.

- Users may download and print one copy of any publication from the public portal for the purpose of private study or research.

- You may not further distribute the material or use it for any profit-making activity or commercial gain

- You may freely distribute the URL identifying the publication in the public portal

If you believe that this document breaches copyright please contact us providing details, and we will remove access to the work immediately and investigate your claim 


\title{
Scoping a PIM System: A Supporting Framework
}

\author{
L. Battistello ${ }^{1}$, K. Kristjansdottir ${ }^{1}$, L. Hvam ${ }^{1}$ \\ ${ }^{1}$ Department of Management Engineering, Technical University of Denmark, Kgs. Lyngby, Denmark \\ (lobatti@dtu.dk, katkr@dtu.dk, lahv@dtu.dk)
}

\begin{abstract}
This article presents a four-step framework for supporting the scoping phase of a product information management system (PIM) and describes the results from applying the framework in an international company. The framework is based on the literature, developed in collaboration with industrial partners and tested in a multidivision and multimarket company. The framework is intended to: (1) identify the stakeholders of the PIM; (2) collect the stakeholders' requirements; (3) give an understanding of the current working process; (4) suggest a future scenario with the implementation of the software; and (5) framing a centralized product information model. The information on the PIM system are lacking in the literature and no studies were found on the scoping process of this software. This study fills that gap by developing and testing a framework to support a PIM project in the scoping phase.
\end{abstract}

Keywords - Product Information, PIM, Scoping Phase.

\section{INTRODUCTION}

Product information is created across the organization and used by different department/stakeholders [1]. Product data is stored and managed in numerous different systems such as Product Lifecycle Management (PLM), Product configuration software (PCS), Enterprise resource planning (ERP) and Customer Relationship Management $(\mathrm{CRM})$ [2][3][4]. Owing to the rapid growth of ecommerce and online stores, companies have to collect and manage clear basic product information that customers can understand [1]. Customers expect product information that is comprehensive, complete and accurate, therefore, the quality and the completeness of product information are of primary importance [5]. The supporting application for managing the customeroriented product information is the Product Information Management system (PIM). The PIM system is a category of dedicated applications focused on centrally managing information about products that support product processes and departments, with a focus on the customer-oriented product information (the data required to market) [1][5].

The PIM system is a relatively new type of software [1], that is rarely studied in the literature; furthermore, there are no indications on how to do the scoping of the project. The decisions taken in the early stages of a PIM project are very important for the success of the entire project and they significantly affect the successive stages. Therefore, the contribution of this paper is to propose and validate through a case study a framework that supports the scoping phase of the software.

\section{LITERATURE REVIEW}

The information about the PIM system are defective in the literature; the only works founded are the book of Abraham [1] and some white papers from Ventana Research [6]. The need to share information across the enterprise and supply chains is driving data to be increasingly exposed and shared. This leads to inconsistencies and incompatibilities between data. The goal of the PIM system is to unify and synchronize disparate product information data and deliver a single version of the truth [1][6].

The examples shown in the literature about the implementation of a PIM system are referred to international large companies such as Coca-Cola HBC, Nikon Europe, Thomas Cook, and etc. [1]. These companies are distributed in space and/or composed of legally different units. Kovács \& Paganelli [7] named this type of companies "virtual extended enterprises". The basic characteristic of these enterprises is that the cooperating units of them keep their independence during the life-cycle of the co-operation [7]. In these cases, the complexity of managing the product information is higher as well as the need to implement a PIM system.

The Rational Unified Process (RUP) methodology is a software development process that supports the early phases of an IT project. It contains development techniques and approaches such as Unified Modelling Language (ULM), architecture modeling, etc. [8]. However, generic development methods, such as the RUP, are not necessarily suitable for every type of project and require content specific adjustments [9].

\section{METHODOLOGY}

The purpose of this research is to develop and test a framework for scoping PIM systems. The development of the framework is based on the related literature review and based on industrial experience. A combination of IT project frameworks and case studies were used; with specific regard to general theory on management of product information, general theory on scoping IT systems, frameworks for scoping IT systems from the Rational Unified Process (RUP) [8] and case studies about scoping PLM systems and product configuration systems [3][10][11]. The framework was developed in collaboration with practitioners, PIM consultants and by 
professors with a research background in product information management and product modelling.

The main goal of the empirical section of this research is to validate the framework in a real context. Thus, the empirical part is a field study on scoping a PIM system. The case company chosen is a manufacturer of mineral wool insulation materials, referred to as insulation company, with sales and production in North America, Europe and Asia. The choice of the setting was made considering a company that felt the need to implement a PIM system and consequently had already made the choice to invest in this project. The company had not yet started the scoping phase but had only made a preliminary analysis and evaluated the PIM project as a primary importance task. Furthermore, the company is an extended enterprise, such as the cases studied in the literature. The suggested framework was tested and further improved in a close cooperation with the PIM project team in the company.

The role of the researcher was to actively participate in all the meetings of the project, taking notes of the relevant aspects, as challenges, limitations, needs, results, etc. The time between the meetings was used by the researcher to understand and note the strengths and the weaknesses of the framework. The testing was carried out within a period of three months in 2017, during which 33 meetings were conducted: 2 workshops with all the stakeholders, 10 catch-up weekly meetings with the project team, 2 steering group meetings with the steering committee and 19 meetings with individual stakeholders.

\section{THE FRAMEWORK}

The proposed framework for scoping PIM systems includes the following four macro activities:

- Stakeholders identification [1][10][12]

- As-Is analysis [8][10][11][12]

- To-Be proposal [8][10]

- Vendor selection phase preparation

The macro activities should be followed in sequence, because it facilitates the gradual and harmonic development of the project. Every step has well-defined purposes and deliverables.

\section{A. Stakeholders Identification}

A PIM system has many different users and it can be used by the entire value chain. In the scoping phase, it is important to include the representatives of all the stakeholders. The aims of this macro activity are: to define the project organizational structure and the main responsibility inside the project, to create an overview of who is involved in the project and the impact across the company, to define a group of people who provides guidance, direction and control of the project and to create an awareness base-knowledge of PIM.

The fist activity consists in the identification of all the possible stakeholders of the PIM system [12]. To have a clear overview, a classification of the stakeholders may be done (for example, stakeholders can be divided in core stakeholders and secondary stakeholders; in a multimarket and multi-division company, the stakeholders can be classified in divisions, departments and markets). The following activities are the identification of the "PIM specialist", the PIM project team and the steering committee [1]. The PIM specialist supports the project manager and the business owner during the scoping phase. He/she should have a base-knowledge of PIM and experience in the implementation of IT systems. He/she can be internal or external. The PIM project team is the core group that manage the full scoping phase; it should comprise at least the project manager, the PIM specialist and the business owner of the project. The steering committee should be composed of decision makers with financial and managerial authority. The first macro activity ends with a "kick-off meeting": it is the first workshop with the project team and the main stakeholders of the project. The purpose of this meeting is to formally notify all team members and stakeholders that the project has begun and to make sure everyone has a common understanding of the project and their roles.

The deliverable of the stakeholders identification phase is a well-defined project organizational scope and structure, where the organizational units and the members who represent them are stated for the project realization.

\section{B. As-Is Analysis}

The As-Is analysis aims to give an understanding of the current working processes [10] and it is divided in four activities:

- Organizational business context introduction;

- Identification of the stakeholders' requirements;

- Data localization and ownership;

- Product model identification.

In the organizational business context introduction activity, the aims are: to understand the key business drivers, the marketspace and the generic targets of the company, the identification of the customers of the company and the identification of the main touchpoints for product information (both digital and physical).

The goals of the second activity, identification of the stakeholders' requirements, are to identify the problems and the unmet needs of the stakeholders regarding product information management and to identify the functionalities of the PIM system that could be relevant for the stakeholders [12].

The aim of the data localization and ownership activity is to understand which product information data are available, how they are currently managed, where they are stored (database, application, etc.) and who has the ownership of these data (department, unit, market, etc.). An overview of the currently IT architecture becomes essential because it helps to understand in which application the data are located [8][10]. 
In the last activity, product model identification, the objectives are to identify the existing taxonomy of the products and to collect the different product models of the different divisions/segments of the company [10]. Nevertheless, not all the divisions of the company may have an own product model; in this case, it is important to build a draft of product model with the collected information. With taxonomy, we mean a classification of the products that organizes them for a variety of purposes.

The four activities mentioned above consist of one or more direct interviews with all the stakeholders. The duration of the interviews may vary across stakeholders.

The deliverables expected for the As-Is analysis macro activity are: a collection of the stakeholders' needs and the PIM system functionalities that the stakeholders expect; an unpolished product data flow diagram, where it is possible to see an overview of the systems and the applications involved in the product information management; and, for each division, a list of the product attributes that are usually provided to the customers.

\section{To-Be Proposal}

The third macro activity is meant to identify the common stakeholders' needs, to identify and mediate the conflict of interest between stakeholders, to suggest a "tobe” IT architecture with the integration of a general PIM system and to propose a single product model representing all the division.

This phase is conducted by the project team, with some interaction to the stakeholders when some clarifications are needed. The first action is to identify, from among the needs that arose from the dialogue with stakeholders, those on which it is possible to satisfy. Some trade-off between different needs are necessary. While in certain case it is easy to solve these trade-off, in others there is a conflict to resolve. The difference between this action and the Identification of the stakeholders' requirements action in the As-is analysis is: while in the first one all the possible needs and opportunity are listed, in the second one it has to be understood which of those are important to satisfy. The second activity consist in the development of the proposal of a future IT architecture with the implementation of a PIM system [8][10]. In the scoping phase, it is better to evaluate the introduction of a general PIM system, without considering special functionalities of a specific software. The proposal shows how the product information data will be exchanged between systems and applications after the implementation of the PIM. The last activity is the single product model framing. Starting from the product models collected or built in the previous macro activity, it is relevant to find and/or develop the frame of a single product model that can represent all the products of the company. It is possible to choose one of the existing product models, if it fits all the division, or develop a new one. The result of this activity is a frame and not the definitive single product model, which will be developed after the vendor selection phase.
The deliverables of the to-be proposal macro activity are: a classification in order of importance of the stakeholders needs that shall be met, an unpolished product data flow diagram of the "to-be proposal" and a frame of the single product data model.

\section{Vendor Selection Phase Preparation}

The last macro activity aims to communicate to the stakeholders the work that has been done in the previous steps (as-is analysis and to-be proposal) and prepare them to next phase, the vendor selection.

A new workshop with all the stakeholders is now needed for two main reasons: first, to explain them the previous work conducted, in particularly the As-Is analysis, the problems and needs that have arisen and the To-Be proposal. The scoping phase is reaching the end; therefore, it is relevant that all the stakeholders know and agree with the outputs of the To-Be proposal macro activity. Second, to introduce the stakeholders to the vendor selection phase, explaining to them what are the future actions (for example meeting with the vendors, demo demonstrations, etc.), and how to evaluate a PIM system (interface, implementation, IT performance, PIM functionalities, etc.). The stakeholders should be prepared to ask the appropriate questions during the meetings with the vendors, and to understand if the functionalities of the different systems can fit their needs.

The deliverable of this last step is a shared agreement between stakeholders and the PIM project team about the requirements to satisfy with the implementation of the PIM system.

\section{RESULTS}

The proposed framework has been applied in a real context to assess its functionality.

\section{A. Stakeholders Identification}

In this case, 17 different stakeholders were identified. They were classified in four groups: divisions, departments (e.g. marketing, group development, etc.) markets (Italian market, North American market, etc.) and "owners" of the IT platforms (ERP, e-commerce, etc.) (fig. 1). Divisions are parts of the company that are separated along product.

The company decided to hire an external consultant for the role of PIM specialist. He was part of the PIM project team with the business owner of the project and the project manager. The steering committee was composed by five people: the group marketing president, a business units' representative, the chief information officer, the chief financial officer and the product manager.

Once the stakeholders and the PIM project team were defined, a 5-hour workshop with them, called kick-off meeting, was conducted. 


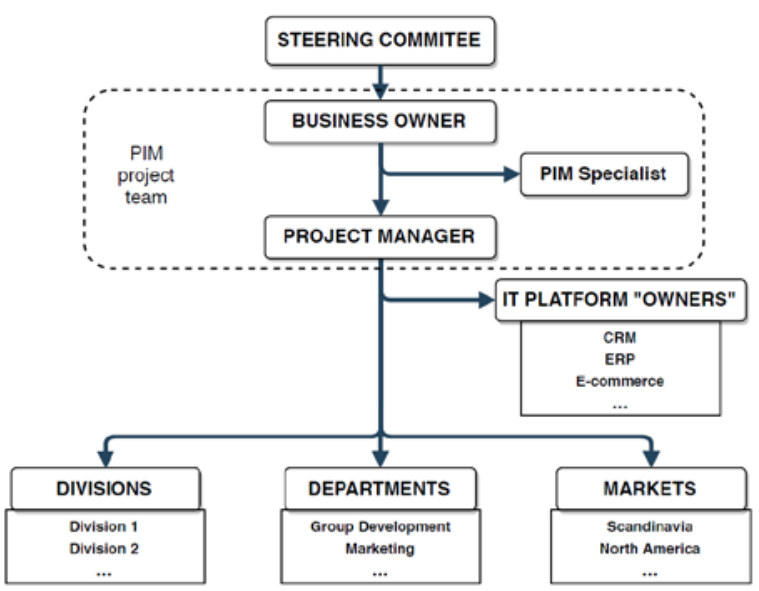

Fig. 1. Project organizational scope and structure

The workshop goals were to explain to the stakeholders the roles of each member, the functionalities of the PIM systems and the organizational structure.

The main challenge of this macro activity was the planning of the kick-off meeting: the different stakeholders were based in different areas of the world and it was relevant that most of them were present in person at the workshop.

\section{B. As-Is Analysis}

The collected requirements for the PIM system vary across stakeholders. However, common needs were identified: accessing to updated product information, having a shared product information HUB (single source of truth) and defining a clear ownership and governance on product information across divisions and markets. During the identification of the stakeholders' requirements, the MoSCoW (Must have, Should have, Could have, Won't have this time) prioritization technique was used. In this way, the users indicated which requirements are of high, medium or low importance.

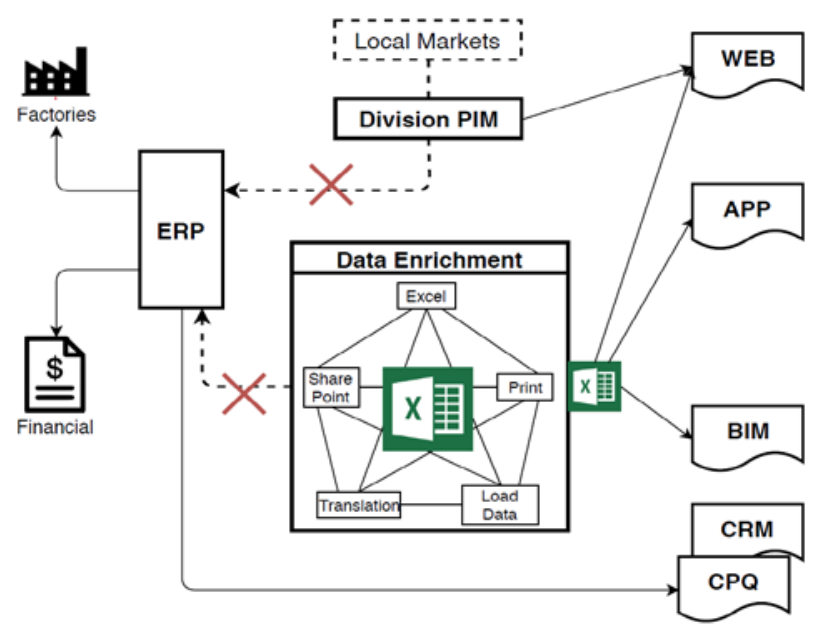

Fig. 2. As-Is unpolished product information data flow diagram
To have a comprehensive overview of the current situation, a flow diagram was framed with the information gathered from the interviews. Figure 2 shows a diagram of the current product information data flow: the current product data enrichment is to a large extent based on manual ad-hoc process steps with multiple market localization and limited support of digital touchpoints. Consequently, there is inconstancy in product information and documentation, marketing is prone to redundant processes by using local Excel sheets and repositories to comply with growing needs for enrichment and documentation, and the individual touchpoints are supported by individual repositories with limited integrations and governance on data distribution.

During the interviews, a collection of 502 different product attributes were gathered. This assortment is the starting point to estimate the size of the PIM system to be implemented.

\section{To-Be Proposal}

The project team suggested a To-Be IT architecture with the integration of a PIM system (fig. 3): the PIM works as a centralized product marketing HUB, which distributes product catalogs to the individual digital touchpoints (i.e. website, e-commerce, building information modeling (BIM), etc.). PIM is sourcing product information from the ERP system and other sources (e.g. digital asset management (DAM)) and delivers process support and tools to produce marketing product information for a "single points of truth across channels" on the aggregated product information. The ERP owns the product entity and the PIM owns the further enrichment of the product.

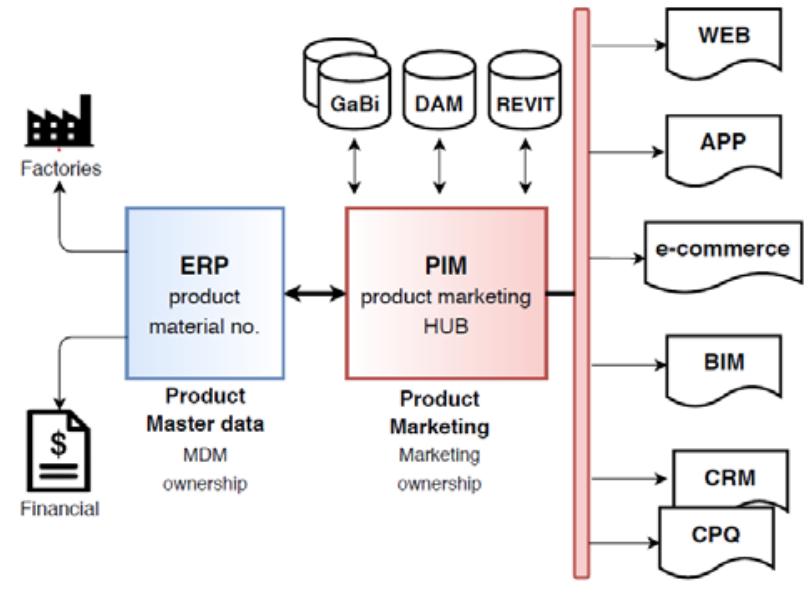

Fig. 3. To-Be unpolished product information data flow diagram

The next step was to frame a centralized product information model with the flexibility to embrace the full range of business units and divisions within the company (fig. 4). The product information model is designed to organize the multiple levels needed to logically enrich and manage product variations within a related range of 
products (product line). The product model is composed of six level: business unit/division, product line, family, product, product variation and material number. A product line is a general group of branded products typically related to a segment, a product family is a group of products for either a specific segment or application type, product is referred to a single product variation level and material number is the ERP data entity.

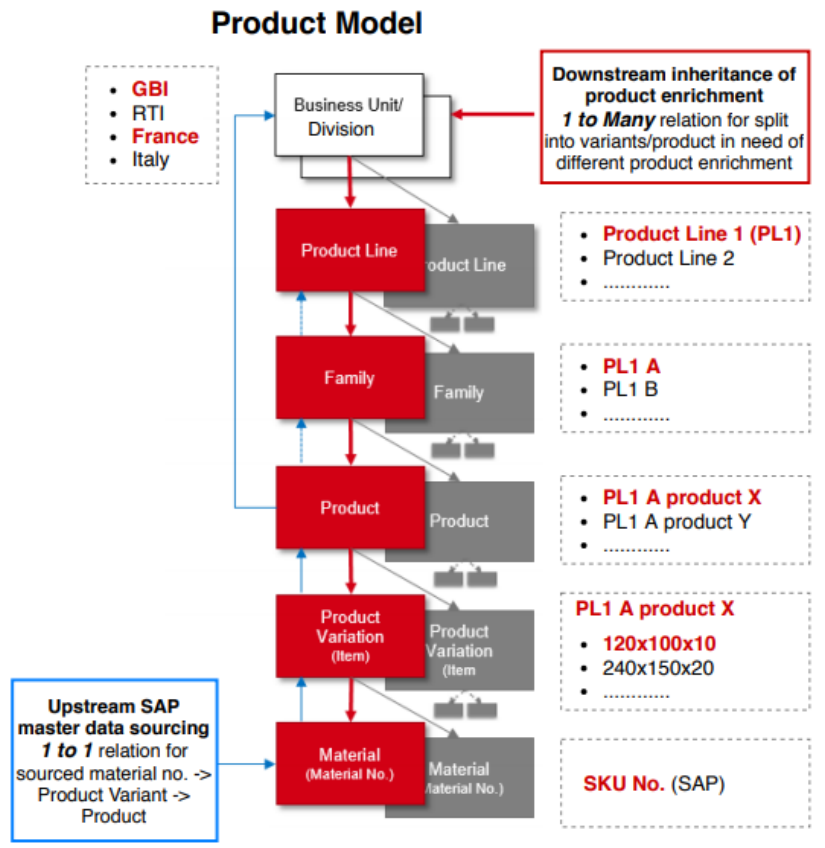

Fig. 4. Frame of the centralized product information model

\section{Vendor selection Phase Preparation}

The scoping phase was concluded with an overall workshop where all the stakeholders were present. The meeting lasted 3 hours and was divided in two section. In the first one, the project team presented the results of the previous macro activities to the stakeholders and explained them the reasons of some decisions. In the second part, instead, the users were introduced to the future step, the vendor selection phase.

\section{DISCUSSION \& CONCLUSION}

The scoping phase is a common stage for all the different type of software but there is a peculiarity of the PIM system that differentiates it from the other software: the centralized product information model. This model is not usually available at the companies. The frame of the model is shared between divisions and business units; thus, the phase of scoping and organizational structuring is essential for achieving a defined consensus and alignment. This paper introduces a standard framework which is structured in 4 macro activities: 1) stakeholders identification, 2) As-Is analysis, 3) To-Be proposed and 4) vendor selection phase preparation, and validated in a case study in a multidivisional and multimarket international company. The case study demonstrated that the framework leads to reduce the problems that were highlighted in the lacking literature available.

The limitation of this study is that the provided results are based on a single company. The framework should be tested in other companies to understand its validity.

Further studies will include the test of the framework both in other similar companies of the one analyzed in the case study and in different kind of companies (e.g. small companies, mono-division companies, etc.).

The present article provides both implications for research and practitioners. For research, this is the first time that a study about the scoping phase of a PIM system is done. For practitioners, this article provides a guideline to support the early phase of a PIM project in a real context.

\section{REFERENCES}

[1] J. Abraham, Product Information Management - Theory and Practice. Springer International Publishing, Management for Professionals, 2014.

[2] S. J. Fenves, R. D. Sriram, R. Sudarsan and F. Wang, “A Product Information Modeling Framework for Product Lifecycle Management”, in Computer-Aided Design, 2005.

[3] C. Forza and F. Salvador, Product Information Management for Mass Customization: Connecting Customer, Front-Office, Back-Office for Fast and Efficient Customization, Palgrave Macmillan, New York, 2007.

[4] D. O’Leary, Enterprise Resource Planning Systems Systems, Life Cycle, Electronic Commerce, and Risk. Cambridge University Press, Cambridge, UK, 2000.

[5] Ventana Research, "Building High-Quality and Complete Product Information, Using Best Practices and Technology Investments to Optimize Product Value", White Paper, 2018.

[6] M. Boyd, "Product Information Management - Forcing the Second Wave of Data Quality”, White Paper, 2006.

[7] G. L. Kovács \& P. Paganelli, "A planning and management infrastructure for large, complex, distributed projectsbeyond ERP and SCM", in Computers in Industry, vol. 51, pp.165-183, 2003.

[8] P. Kruchten, The Rational Unified Process: An Introduction. Addison-Wesley, New York, NY, 1998.

[9] T. Gilbt, Principles of Software Engineering Management. Addison-Wesley, Harlow, UK, 1988.

[10] S. Shafiee, L. Hvam and M. Bonev, "Scoping a product configuration project for Engineer-To-Order companies", in International Journal of Industrial Engineering and Management (IJEM), 2014.

[11] S. Shafiee, K. Kristjansdottir, L. Hvam and C. Forza, "How to scope configuration projects and manage the knowledge they require”, in Journal of Knowledge Management, 2018.

[12] D. Dvir, T. Raz and A. Shenhar, "An empirical analysis of the relationship between project planning and project success", in International Journal of Project Management, vol.21, No.2, pp. 89-95. 